\title{
A RELAÇÃO TEORIA E PRÁTICA EM PROJETOS DE EDUCAÇÃO AMBIENTAL DESENVOLVIDOS EM UM BAIRRO DE BAURU, SP, BRASIL
}

\section{The relationship between theory and practice in environmental education projects in a neighborhood of Bauru, São Paulo, Brazil}

\author{
Lucas André Teixeira ${ }^{1}$. Jandira Líria Biscalquini Talamoni ${ }^{2}$. \\ Marília Freitas de Campos Tozoni-Reis ${ }^{3}$
}

\begin{abstract}
Resumo: Este estudo analisa a relação entre teoria e prática que emerge de dois Projetos Ambientais realizados em um bairro popular de Bauru, SP, Brasil. Para essa análise, diante da diversidade de concepções e abordagens teórico-práticas acerca da educação ambiental, optamos pela fundamentação teórica da vertente crítica. Levando em conta as possibilidades dos procedimentos da pesquisa qualitativa em educação, elegemos a análise de conteúdo para a obtenção dos dados. Os resultados apresentados neste artigo sinalizam a necessidade de se romper com a dicotomia entre a forma (prática) e o conteúdo (teoria) no processo educativo ambiental, dando centralidade aos conteúdos sistematizados e construídos historicamente. Assim, consideramos que os processos educativos ambientais em análise, implicam o tratamento da forma e conteúdo como uma unidade dialética.
\end{abstract}

Palavras-chave: Educação ambiental. Projeto ambiental. Processo educativo. Teoria e prática.

\begin{abstract}
This study examines the relationship between theory and practice that emerges from two Environmental Projects that were carried out in a popular neighborhood of Bauru, SP, . In order to analyze the data, given the diversity of theoretical and practical approaches and concepts in environmental education, we chose as a theoretical foundation critical environmental education. Considering the techniques used in the methodological procedures of qualitative research in education, we elected, as a tool to collect information, content analysis. The results presented in this paper indicate the need to break the dichotomy between form (practice) and content (theory) in the environmental educational process, focusing on the systematized and historically constructed contents. Thus, we consider the environmental education process analyzed involve treating form and content as a dialectic unit.
\end{abstract}

Keywords: Environmental education. Environmental project. Educational process. Theory and practice.

\footnotetext{
${ }^{1}$ Universidade de São Paulo (USP), Núcleo de Pesquisas em Novas Arquiteturas Pedagógicas, São Paulo, SP, Brasil. Avenida Cruzeiro do Sul, 3-30, ap. 207, Bl. II, Vila Cardia, Bauru, SP, CEP 17013-680, Brasil. E-mail: lucasandreteixeira@gmail.com

${ }^{2}$ UNESP - Univ. Estadual Paulista, Faculdade de Ciências, campus de Bauru, Bauru, SP, Brasil.

${ }^{3}$ UNESP - Univ. Estadual Paulista, Instituto de Biociências, campus de Botucatu, Departamento de Educação, Botucatu, SP, Brasil.
} 


\section{Introdução}

A educação ambiental é um processo educativo que objetiva a instrumentalização ${ }^{4}$ dos sujeitos para o enfrentamento da crise socioambiental, buscando suas causas nas condições do modo de produção atual, compreendido como determinante da crise a que está submetida a humanidade.

Diante dos desafios e afrontamentos que estão postos pela realidade do mundo contemporâneo, especialmente no que tange à problemática ambiental, entendemos que a educação ambiental cumpre diversas funções na sociedade atual, contraditoriamente atreladas a concepções políticas e ideológicas que visam satisfazer o interesse de instituições políticas, comerciais, industriais, escolares, culturais, entre outras.

Os Projetos Ambientais analisados neste estudo estiveram fundamentados em alguns pressupostos filosófico-políticos que focaram o processo educativo escolar e buscaram uma articulação entre as atividades teóricas (conteúdo) e práticas (forma) relacionadas ao meio socioambiental, sobretudo em relação à problemática ambiental enfrentada pelo bairro onde foram desenvolvidos. Nosso objetivo foi o de analisar as relações entre a teoria e a prática presentes no processo educativo ambiental, buscando o aprofundamento da reflexão sobre alguns de seus princípios na perspectiva da educação ambiental crítica.

\section{A educação ambiental crítica}

A educação ambiental pode ser apropriada a partir das "diferentes abordagens teórico-práticas ${ }^{5}$, formuladas e praticadas por diferentes grupos sociais, com interesses contraditórios histórica, social e politicamente determinados" (TOZONI-REIS, 2007, p. 185). Neste sentido, entendemos ser necessária uma reflexão mais elaborada e rigorosa, por parte dos educadores, no modo de se conceber a educação ambiental diante de tal polissemia.

${ }^{4}$ É importante destacar que o termo "instrumentalização", que será utilizado ao longo deste estudo, está relacionado às formulações de Dermeval Saviani, referindo-se aos "instrumentos teóricos e práticos necessários ao equacionamento dos problemas detectados na prática social” (SAVIANI, 2006, p. 71) dos sujeitos, que nada mais são que as "ferramentas culturais necessárias à luta que travam diuturnamente para se libertar das condições de exploração em que vivem” (SAVIANI, 2006, p. 71). Estas ferramentas devem ser apropriadas de forma que sirvam de instrumentos para a prática social transformadora dos sujeitos. ${ }^{5}$ Esta polissemia de abordagens teórico-práticas foi sistematizada nos estudos elaborados por Tozoni-Reis (2007), que destaca várias abordagens na compreensão da educação ambiental, classificadas e denominadas em diferentes categorias e que resultam em diferentes práticas educativas ambientais, sintetizando-as em alguns grandes grupos: "a educação ambiental como promotora das mudanças de comportamentos ambientalmente inadequados - de fundo disciplinatório e moralista; a educação ambiental para a sensibilização ambiental - de fundo ingênuo e imobilista; a educação ambiental centrada na ação para a diminuição dos efeitos predatórios das relações dos sujeitos com a natureza - de caráter ativista e imediatista; a educação ambiental centrada na transmissão de conhecimentos técnico-científicos sobre os processos ambientais que teriam como conseqüência uma relação mais adequada com o ambiente - de caráter racionalista e instrumental" (TOZONIREIS, 2007, p. 179), bem como a educação ambiental crítica, a qual definiremos ao longo deste estudo. 
Para avançarmos em nossas discussões e justificarmos a concepção de educação ambiental que assumimos neste estudo, nos remeteremos a Grün (2007), que discute a epistemologia da educação ambiental a partir de uma concepção filosófica. Seguindo este autor, a necessidade do 'predicado ambiental' na educação surge devido à negação do ambiente durante a trajetória histórica da educação moderna. Assim, a utilização do 'predicado ambiental' na educação tem um caráter histórico, resultando em um processo educativo que visa a considerar e responder à crise da cultura ocidental que, durante a modernidade, se 'esqueceu' do nosso vínculo indissociável com o ambiente, negando, assim, a própria história da humanidade.

Nesta linha de raciocínio, para construirmos uma reflexão no campo epistêmico da educação ambiental, temos que ressignificar os valores do racionalismo moderno sob o qual repousam as principais características da crise ecológica proporcionada pelo capital que, consequentemente, determina e estimula a relação inadequada da humanidade com o seu entorno.

Assim, podemos afirmar que o racionalismo cartesiano que se desenvolveu, durante toda a idade moderna, como referência teórico-metodológica hegemônica para a ciência, criou um contexto totalmente favorável para o desenvolvimento do capitalismo, onde as "relações de mercado, natureza e lógica temporal antropocêntrica passam a formar um sistema complexo de inter-relações" (GRÜN, 2007, p. 25). Foi desta maneira que o racionalismo humano passou a mercantilizar a natureza, criando um locus que proporcionou as bases para o desenvolvimento da sociedade moderna.

O racionalismo cartesiano provocou uma cisão radical entre o sujeito e o objeto, lógica na qual se baseou todo o conhecimento científico da idade moderna, bem como toda a cultura ocidental (GRÜN, 2007). Essa lógica transformou a natureza em objeto e o homem passou a dominá-la para poder explorá-la, apossando-se da mesma e, consequentemente, distanciando-se dela. Essa lógica também favoreceu o desenvolvimento da sociedade capitalista e, ao longo de seu desenvolvimento, chegou a determinar a exploração do homem pelo homem para a criação de uma "sociedade descartável" (MÉSZÁROS, 1989 apud LOUREIRO, 2004, p. 94), em que os bens não são produzidos para atender às necessidades humanas de sobrevivência, mas com a utilidade definida no domínio do valor de troca.

Este espectro que rondava a modernidade também influenciou profundamente a educação moderna. Para tornar-se humano, o homem deveria dominar a natureza e libertar a si mesmo. Assim, o desenvolvimento das Ciências Naturais baseou-se na distinção entre o sujeito e o objeto, na medida em que o pensamento curricular passou a se fundamentar em uma lógica pragmática, individualista e racionalista, estruturas que consideravam a natureza apenas quanto ao seu valor de uso (GRÜN, 2007).

A consolidação da influência da racionalidade moderna na educação foi efetivada com a mecânica newtoniana, que estabeleceu uma nova visão de mundo, na qual todas as explicações se baseavam no modelo explicativo da mecânica clássica. Sobre esse aspecto, Grün (2007, p. 41) diz que:

A possibilidade de uma descrição objetiva da natureza estabelecida pelo programa newtoniano não define um simples conceito de natureza. Esta possibilidade define um modelo de interpretação do mundo sustentado no modelo explicativo mecânico-causal. O modelo atomístico reducionista estabelecerá nas estruturas conceituais dos currículos e, 
mais do que isso, ele passará a ser a única forma possível de conceber a realidade. De um certo modo, ele passa a ser a própria realidade. Neste período todo um corpo de saberes ecologicamente sustentáveis é deixado de lado no currículo por não ser científico, ou seja, por não ser mecanicista.

Diante disso, podemos perceber que a racionalidade moderna suprimiu diversos valores que eram contrários ao paradigma mecanicista e muitos dos saberes que não se enquadravam nesse paradigma foram negados. Esses saberes foram suprimidos no período renascentista - entre os séculos XV e XVI -, silenciando as concepções aristotélicas do período medieval, que exaltavam o retorno do homem à natureza. Posteriormente a este período, já no século XVIII, podemos identificar a concepção e elaboração de valores que traziam à tona o retorno do homem à natureza, como podemos observar nas formulações de Rousseau (1974, p. 90 apud HERMANN, 2006, p. 93):

A superfície da terra elevava minhas idéias a todos os seres da nature$\mathrm{za}$, ao sistema universal das coisas, ao ser incompreensível que abarca tudo. Então, com o espírito perdido nessa imensidão eu não pensava, não raciocinava, não filosofava mais; me sentia com um tipo de voluptuosidade, oprimido pela força desse universo, me abandonava com encantamento à confusão dessas grandes idéias; gostava de me perder em imaginação no espaço; meu coração confinado nos limites dos seres, se encontrava ali muito apertado, me sufocava no universo e queria me lançar ao infinito.

Esta autora (HERMANN, 2006) lembra que Rousseau foi um dos pensadores que mais influenciou o nosso tempo, sobretudo pela contribuição de sua proposta educativa que se contrapôs ao pensamento iluminista daquela época, com uma proposta educativa inovadora, estabelecendo a natureza como fio condutor para empreender uma reforma moral e intelectual da sociedade.

Esta contraposição ao corpo de saberes iluministas poderia ter apresentado alternativas ou possibilidades contrárias ao modelo de desenvolvimento da época, sobretudo nas relações entre o homem e o ambiente, mas, como o homem necessitava se distanciar da natureza para conquistar sua autonomia, não se preocupava com as consequências da apropriação que dela fazia.

No que diz respeito à educação, qualquer saber que não tivesse uma legitimidade científica mecanicista não tinha valor algum, o que reforçava a crise societária da modernidade. Neste contexto, a problemática ambiental ganhou grande destaque no cenário mundial, sobretudo na segunda metade do século XX, quando surgiu o movimento ambientalista (GRÜN, 2007).

Sob esta perspectiva, entendemos que a problemática ambiental se estruturou e se intensificou a partir da racionalidade moderna, e que é 
[...] um problema estrutural, vinculado ao modelo de desenvolvimento, ao modo de produção, à baixa participação política e cidadã nas questões vistas como ambientais, à conjunção do Estado aos interesses privados e mercantis, e ao reducionismo no tratamento da categoria ambiente. (LOUREIRO, 2004, p. 82)

Neste sentido, entendemos que o processo educativo é objeto da educação ambiental, na medida em que busca possibilitar que o conhecimento histórico prepare o homem para compreender suas necessidades e as do ambiente em que vive e onde convive com outros iguais ou não, ou seja, para compreender a totalidade e instrumentalizar-se para atuar nas transformações sociais que se fazem necessárias.

A educação ambiental, enquanto processo educativo voltado para a prática social do sujeito, deve assumir a necessidade de rompimento com o paradigma hegemônico. Entretanto, Loureiro (2006, p. 136) afirma que "a construção de um paradigma que se afirme ecológico não se esgota em mudança na forma de pensar"; o que significa dizer que este rompimento faz parte de um projeto político a ser concretizado pelos educadores, tendo, no horizonte, a ruptura com o modelo de sociedade vigente. Em resumo, entendemos que:

[...] em termos políticos e pedagógicos, o resultado direto dessa forma de pensar é a aceitação de que a mudança ocorre dentro do sistema, mas não do sistema. O que representa querer mudar indivíduos sem mudar instituições, construir um novo mundo sem romper com o capitalismo, educar para uma boa conduta sem que sejamos críticos e reflexivos cotidianamente e agentes da transformação societária. Posições frágeis que esvaziam a historicidade humana e reforçam a linearidade na leitura do mundo. (LOUREIRO, 2006, p. 140-141)

Diante da diversidade de propostas teóricas produzidas no âmbito da educação ambiental, cabe-nos questionar a validade das mesmas, em termos prospectivos, para podermos propor uma reversão ou buscarmos respostas para a problemática ambiental. Entendemos que a negação da homogeneidade simplificadora e o respeito à diferença de ideias são imprescindíveis e coerentes com a visão de ambiente enquanto complexidade do mundo, pois este é decorrente de múltiplas determinações; entretanto, ao se defender o diverso, não se pode cair num pluralismo indiferenciado, o que também seria um erro (LOUREIRO, 2004).

Assim, qualquer proposta ou atividade de educação ambiental que adote uma perspectiva de enfrentamento radical da problemática ambiental deve ser mediada a partir de reflexões sobre os seus fundamentos e conceitos, com a devida coerência, para que não venha a legitimar as contradições produzidas pelo modo de produção capitalista que, muitas vezes, nem são trazidas à tona pelos projetos que tematizam o ambiente.

É neste sentido que propomos uma profunda e rigorosa reflexão sobre os fundamentos teóricos da educação ambiental que problematiza as tendências teóricas e as práticas educativas, proporcionando reflexões sobre as suas contradições e, consequentemente, apontando para a necessidade de mudança qualitativa nos processos determinantes da problemática ambiental que se materializa na organização social. 
Toda essa reflexão foi necessária para nos comprometermos com a posição que assumimos neste estudo. Diante das diversas concepções e abordagens teórico-práticas existentes no modo de se conceber a educação ambiental, acreditamos que os princípios deste processo educativo, sob a perspectiva crítica, podem criar condições para o enfrentamento da crise estrutural que estamos vivenciando a cada dia, resultante do modo de produção capitalista, entendendo a educação ambiental crítica como:

[...] um processo político de apropriação crítica e reflexiva de conhecimentos, atitudes, valores e comportamentos que tem como objetivo a construção de uma sociedade sustentável do ponto de vista ambiental e social - a educação ambiental transformadora e emancipatória. (TOZONI-REIS, 2007, p. 179)

Os projetos analisados neste estudo tiveram sua origem no âmbito escolar, portanto, iniciaremos nossa discussão focando os princípios da educação ambiental no contexto escolar.

Acreditamos que as práticas educativas em educação ambiental não podem estar voltadas somente para as resoluções imediatas e pontuais dos problemas ambientais locais. Diante disso, entendemos que o processo educativo, na perspectiva da educação ambiental crítica, é um elemento de transformação social que possibilita o enfrentamento, e não apenas a resolução imediata de problemas socioambientais pontuais, assumindo a finalidade de promover ações que contribuam para o enfrentamento da problemática ambiental a partir de uma perspectiva histórica.

Este ponto de vista vincula a educação ambiental, especificamente, ao enfrentamento pedagógico da questão ambiental, pois a pedagogia "como ciência da e para a educação, se preocupa com a compreensão teórica e prática dos processos educativo-formativos e diz respeito aos saberes e modos da ação voltados para a formação humana" (TOZONI-REIS, 2007, p. 186). Entendemos, portanto, que a educação ambiental é um processo educativo e pedagógico que visa à articulação entre a teoria (conteúdo) e a prática (forma), como possibilidade de promoção do homem.

É neste sentido que o ensino formal e os processos que nele ocorrem são de fundamental importância para a educação ambiental crítica. No entanto, a educação ambiental, enquanto processo educativo, não pode se fundamentar numa prática educativa e pedagógica pautada em uma apropriação distorcida, simplificadora e reducionista dos agentes e causadores da problemática ambiental, pois, neste caso, se enquadraria no que Saviani (2006) definiu como sendo apenas teoria crítico-reprodutivista, na qual o processo educativo reproduz as relações de exploração capitalista.

Com o objetivo de avançar para além das perspectivas pedagógicas produzidas, legitimadas e reforçadas pelas contradições e desigualdades produzidas pelo capital, sobretudo em relação à problemática ambiental, buscaremos uma articulação entre a educação ambiental crítica e a pedagogia histórico-crítica formulada por Dermeval Saviani, pois, como o próprio autor frisa: 
A pedagogia histórico-crítica vai tomando forma à medida que se diferencia no bojo das concepções críticas; ela diferencia-se da visão crítico reprodutivista, uma vez que procura articular um tipo de orientação pedagógica que seja crítica sem ser reprodutivista. Esta colocação parece-me importante em boa parte dos debates que se travaram e das objeções que se levantaram a essa tendência, que acabaram desconsiderando que ela está além do crítico-reprodutivismo, e não aquém. (SAVIANI, 2005, p. 65)

Nesta perspectiva, os saberes voltados para a formação humana do indivíduo exigem que o professor tenha uma prática educativa focada nas relações sociais historicamente estabelecidas pelos sujeitos em sociedade. Uma pedagogia crítica, sem ser reprodutivista, pode contribuir para uma educação ambiental que visa ao enfrentamento dos problemas socioambientais gerados pelo capital e produzidos e objetivados socialmente ao longo da história.

Esta condição exige do professor, que adquire a condição de um agente social ativo, um comprometimento político com as transformações da sociedade. Desta forma, considerando que o trabalho educativo produz intencionalmente, em cada ser singular, o que de humanidade foi gerado e produzido histórica e coletivamente até o seu momento de realização (SAVIANI, 2005), o professor tem possibilidades de criar condições para que o sujeito se aproprie criticamente dos conteúdos culturais produzidos historicamente, por meio de um processo educativo dialógico que articule a prática e a teoria, a forma e o conteúdo.

Certamente, podemos perceber que os processos educativo-formativos inspirados na perspectiva teórica da pedagogia histórico-crítica estão alinhados com a perspectiva da educação ambiental crítica que assumimos neste estudo, visto que:

[...] se a educação é mediadora na atividade humana, articulando teoria e prática, a educação ambiental é mediadora da apropriação, pelos sujeitos, das qualidades e capacidades necessárias à ação transformadora responsável diante do ambiente em que vivem. Podemos dizer que a gênese do processo educativo ambiental é o movimento de fazer-se plenamente humano pela apropriação/transmissão crítica e transformadora da totalidade histórica e concreta da vida dos homens no ambiente. (TOZONI-REIS, 2007, p. 218)

Um dos desafios que se coloca aos educadores que compartilham dessa perspectiva é a tarefa intelectual de formular teoricamente na prática, pela práxis, o compromisso e o comprometimento de criar condições para uma ruptura com as relações socioambientais determinadas pelo modo de produção vigente na prática educativa.

Este desafio requer uma reflexão categórica com o objetivo de ultrapassar as práticas pontuais e imediatistas que querem mudar o pensamento e o comportamento sem mudar a realidade objetiva, ou seja, a organização social. Isto implica fundamentar o agir a partir de reflexões teóricas que qualifiquem a prática, ou seja, pela práxis, levando em conta: 
[...] a atividade concreta pela qual o sujeito se afirma no mundo, modificando a realidade objetiva e sendo modificado, não de modo espontâneo, mecânico e repetitivo, mas reflexivo, pelo auto-questionamento, remetendo a teoria à prática. (LOUREIRO, 2004, p. 130)

Este é o ponto decisivo e desafiador para aqueles que estão comprometidos com a educação ambiental crítica. Isto exige um pensamento reflexivo-dialético - ação-reflexão-ação - sobre a prática social, onde:

[...] a educação é entendida como mediação no seio da prática social global. A prática social se põe, portanto, como o ponto de partida e o ponto de chegada da prática educativa. Daí decorre um método pedagógico que parte da prática social em que professor e aluno se encontram igualmente inseridos, ocupando, porém, posições distintas, condição para que travem uma relação fecunda na compreensão e encaminhamento da solução dos problemas postos pela prática social, cabendo aos momentos intermediários do método identificar as questões suscitadas pela prática social, dispor os instrumentos teóricos e práticos para sua compreensão e solução e viabilizar sua incorporação como elementos integrantes da própria vida dos alunos. (SAVIANI, 2002, p. 263)

Diante dessas reflexões, está colocado o desafio de enfrentarmos os problemas fundamentais da sociedade capitalista. Acreditamos que a educação ambiental crítica nos proporciona condições para caminharmos em direção à superação dos problemas socioambientais, por meio da práxis educativa. Temos claro que não conseguiremos responder e, muito menos, resolver os problemas estruturais da sociedade do capital, já que as transformações da sociedade ocorrem no processo dinâmico e dialético da história. Entretanto, na medida em que a educação ambiental crítica surgir no horizonte dos sujeitos, poderá indicar o caminho para a transformação histórica das relações socioambientais na busca de uma sociedade mais justa e igualitária, e é justamente neste sentido que acreditamos que se deve caminhar.

\section{Metodologia}

O campo de estudos da metodologia qualitativa, definida como procedimento metodológico para este estudo, começou a se estabelecer nas pesquisas antropológicas e sociológicas no limiar do século XIX, ganhando corpus no final deste período, quando as denúncias sociais passaram a ganhar destaque, chamando a atenção para as condições de vida subumanas às quais estava submetida boa parte da população. Tais estudos deram relevância a temas como: pobreza, condições de trabalho, saúde, urbanização e educação, entre outros (BOGDAN; BIKLEN, 1991).

A metodologia qualitativa, assim, busca analisar os problemas apresentados pela realidade social, os quais desafiam-nos à reflexão, objetivando a busca de alternativas para a 
superação dos mesmos. Eis aí a influência da pesquisa qualitativa no campo educacional, quando, no princípio do século XX, começou a ganhar espaço.

Não obstante, percebemos que a influência do racionalismo moderno impera, marcadamente, nos estudos educacionais, e que os fenômenos associados ao processo educativo foram e, de certa forma, ainda são estudados como se estivessem isolados do contexto histórico, político e social da realidade que se pretende investigar, ou seja, "como se fosse um fenômeno físico, para uma análise acurada, se possível feita em um laboratório, onde as variáveis que o compõem pudessem também ser isoladas, a fim de se constatar a influência que cada uma delas exercia sobre o fenômeno em questão" (LÜDKE; ANDRÉ, 1986 p. 3), o que dá espaço a uma neutralidade científica típica das ciências naturais.

Ao longo do desenvolvimento dos estudos na área da educação, ficou claro que a pesquisa educacional tem complexidade e dinamismo próprios, que exigem mais do que um estudo analítico e isolado de algumas variáveis, sendo necessário o suporte de outros métodos de pesquisa que contemplem alguns elementos metodológicos importantes para proporcionar a compreensão dos fenômenos buscada. Assim, a pesquisa qualitativa questiona e supera alguns pressupostos da ciência tradicional, como a neutralidade e a objetividade, sem perder, no entanto, o rigor metodológico. Neste sentido, é importante considerar o envolvimento do pesquisador com o objeto de pesquisa e com o contexto no qual esta se desenvolve, pois este envolvimento passa a fazer parte do processo de construção do conhecimento: "o observador é da mesma natureza que o objeto; o observador, ele mesmo, é uma parte da observação" (LÉVI-STRAUSS, 1975, p. 215).

Partindo dos pressupostos da educação ambiental crítica, este artigo tem sua origem em uma dissertação de mestrado (TEIXEIRA, 2009), na qual o autor analisou sete projetos ambientais desenvolvidos em um bairro popular da cidade de Bauru, SP. Neste artigo trazemos os resultados das análises da relação forma e conteúdo de dois desses projetos, aos quais tivemos acesso e dos quais participamos, que possuíam um registro formal e que foram executados por membros de diversos segmentos da sociedade: universidades, poder público, organizações não governamentais e associação de moradores. Ambos caracterizam-se como projetos - um deles, acadêmico, uma dissertação de mestrado; e outro desenvolvido pelo poder público.

Assim, com base na análise e interpretação dos mesmos, pretendemos, nos limites deste artigo, elaborar conhecimentos que contribuam para a superação da dicotomia existente entre teoria e prática, no enfrentamento da problemática ambiental, por meio do processo educativo, buscando o aprofundamento da reflexão sobre alguns de seus princípios na perspectiva da educação ambiental crítica.

Dentre as possibilidades técnicas utilizadas nos procedimentos da pesquisa qualitativa em educação, elegemos a análise de conteúdo. Esta possui suas raízes nas ciências humanas e tem sido utilizada na maior parte das pesquisas que lidam com dados descritivos, como: entrevistas, documentos, livros e cartas, entre outros passíveis de análise. Assim, "a ênfase não reside na descrição dos conteúdos, mas no que estes poderão ensinar após serem tratados" (BARDIN, 1979, p. 38), portanto, visa ao aprofundamento da análise.

Ao adotarmos esta técnica de pesquisa, procuramos adequá-la aos objetivos iniciais deste estudo. De acordo com Bardin (1979, p. 31), "ao adequá-la ao domínio e ao objetivo pretendidos tem que ser reinventada a cada momento". Dessa maneira, os procedimentos metodológicos utilizados neste estudo foram articulados com os objetivos e com o referencial 
teórico assumidos na expectativa da obtenção de respostas para os questionamentos inicialmente colocados.

Com base na consideração feita por Bardin (1979, p. 119), quando esta salienta que, no processo de categorização, podemos assumir que: "o sistema de categorias é fornecido e repartem-se da melhor maneira possível os elementos, à medida que vão sendo encontrados", para esta pesquisa a categoria preestabelecida foi o processo educativo, visto que os objetivos principais foram: identificar e analisar a relação entre a forma e conteúdo nos processos educativos ambientais presentes nos projetos selecionados para estudo.

Para a identificação das ações que caracterizaram os processos educativos nos projetos ambientais, adotamos as três etapas que Bardin (1979) elege como essenciais na organização da análise de conteúdo: pré-análise, exploração do material e interpretação inferencial. Embora a autora proponha essas etapas, isso não quer dizer que estas sejam estanques, compartimentalizadas e rígidas, pois, na medida em que as realizamos, percebemos que estão totalmente articuladas, sobretudo aos objetivos propostos. Além disso, Bardin (1979) também ressalta que tais etapas podem ser flexíveis, permitindo a introdução de novos procedimentos no decurso da análise.

A pré-análise inclui a organização e sistematização das ideias iniciais da investigação e, segundo Bardin (1979), tem, como primeiro objetivo, a seleção dos documentos a serem analisados. Assim, foram selecionados:

- Projeto acadêmico - Dissertação de mestrado: Atividades de campo em educação ambiental: construção coletiva de diretrizes metodológicas (BALDANI, 2006).

- Projeto do Poder Público: Estudo da qualidade ambiental da microbacia do Córrego Barreirinho: uma contribuição interunidades escolares como ferramenta orientadora para o Plano Diretor Participativo de Bauru - SP (TEIXEIRA, 2006).

Ainda na etapa de pré-análise, a formulação de hipóteses foi o segundo objetivo que, de acordo com Bardin (1979, p. 98), se constituem nas "afirmações provisórias que nos propomos verificar, recorrendo aos procedimentos de análise". Partimos da hipótese de que as diferentes abordagens filosófico-políticas presentes durante a execução dos dois projetos ambientais analisados geraram algumas dicotomias entre a teoria e a prática naqueles processos educativos ambientais desenvolvidos. Assim, ao analisarmos tais processos, buscamos o aprofundamento da reflexão sobre alguns de seus princípios, estabelecendo, como premissa, a centralidade na práxis educativa do educador ambiental.

Uma vez alcançados os objetivos estabelecidos para a etapa da descrição analítica, identificamos o processo educativo presente nos projetos analisados, e passamos para a etapa de exploração do material, para aprofundarmos a análise dos projetos e para obtermos os resultados a serem apresentados a partir dos dados extraídos dos textos e administrados de acordo com as decisões tomadas anteriormente. Como era esperado, já nesta fase surgiram as primeiras inferências para a interpretação dos dados, com base no referencial adotado, ou seja, a relação teoria e prática na perspectiva da educação ambiental crítica. Deu-se início, então, à etapa de interpretação inferencial, que nos propiciou inferir sobre os "conhecimentos relativos às condições de produção; inferência esta que recorre a indicadores" (BARDIN, 1979, p. 38). 
A relação teoria e prática em projetos ...

\section{Resultados e discussão}

Os projetos delimitados para análise neste estudo foram desenvolvidos na Escola Estadual Padre Antônio Jorge Lima, situada no bairro Nobuji Nagasawa, localizado na periferia da cidade de Bauru, SP. Os resultados obtidos estão organizados para apresentação em dois tópicos: Projeto Acadêmico e Projeto do Poder Público.

\section{Projeto Acadêmico}

A dissertação de mestrado de Baldani (2006) foi desenvolvida entre os meses de março a outubro de 2005, e estabeleceu, como principal ação, a construção coletiva de diretrizes metodológicas para o desenvolvimento de aulas de campo em educação ambiental. Por meio desta ação, a pesquisadora visou "contribuir para que os princípios básicos da práxis educativa cultural, informativa, fundamentalmente política, formativa, emancipatória, crítica e transformadora da educação ambiental fundamentem as ações educativas” (BALDANI, 2006, p. 18).

Para atingir os objetivos propostos, o estudo buscou implantar o desenvolvimento de propostas teórico-metodológicas de atividades de campo em um processo de investigação e construção coletivas, junto a um professor e seus alunos de quinta série do Ensino Fundamental. Baldani (2006) visou à construção de diretrizes metodológicas para o desenvolvimento daquele tipo de atividade em educação ambiental, cabendo aqui destacar a nossa participação - como professor de Geografia daquela escola - no processo coletivo e participativo então proposto pela pesquisadora.

Para garantir a coerência teórico-metodológica no desenvolvimento da investigação, o estudo "tomou como referencial metodológico a pesquisa-ação-participativa, abrigada nas metodologias qualitativas de pesquisa" (BALDANI, 2006, p 23). Buscando construir coletivamente as diretrizes metodológicas para o desenvolvimento de atividades de campo em educação ambiental, a pesquisadora constituiu um grupo de pesquisadores comunitários, que a incluía, além do professor de Geografia e seus alunos, para elaborar e realizar, participativa e coletivamente, as atividades de campo.

Em um momento inicial, juntamente com outros professores, discutimos, com a pesquisadora, o desenvolvimento das propostas que tinham como tema gerador as atividades de campo. Nosso posicionamento à época foi, sobretudo, no sentido devoltar a nossa atenção à fundamentação teórica e metodológica envolvida na elaboração das atividades de campo, ou seja, conceituar atividade de campo e analisar os espaços de ação e conteúdos a serem trabalhados, além de outros aspectos que poderiam surgir durante o processo. Sugerimos também, e intuitivamente, a necessidade de se trabalharem as questões teóricas, sobretudo os conteúdos diretamente envolvidos com as atividades que possivelmente desenvolveríamos.

Podemos observar, no trecho apresentado a seguir, que Baldani (2006) entendia que a apresentação da fundamentação teórica específica aos participantes, anteriormente à execução da atividade de campo, criaria dificuldades para a sua execução:

Os professores indicaram mais uma dificuldade em iniciar o trabalho com a participação dos alunos: acreditavam na necessidade de se mi- 
nistrar conteúdos prévios e que, durante este período, paralelamente, poderíamos realizar nossos estudos sobre atividades de campo, elencando possíveis temas a serem trabalhados e visitas/reconhecimento de possíveis espaços a serem explorados. (BALDANI, 2006, p. 32-33)

Atualmente, dispondo de um embasamento teórico e refletindo sobre essa passagem, reafirmamos o nosso posicionamento e crença de que "o trabalho educativo é o ato de produzir, direta e intencionalmente, em cada indivíduo singular, a humanidade que é produzida histórica e coletivamente pelo conjunto dos homens" (SAVIANI, 2005, p. 13). Entendemos, assim, que o processo educativo deve ser intencional e sistematizado, e isto coloca a necessidade de se fundamentarem as atividades, sejam elas de campo ou não, com base nos conteúdos envolvidos em uma determinada proposta.

A pesquisa de campo como tema gerador pode até adotar estratégias no sentido de não se trabalhar o conteúdo previamente em sala de aula, podendo este ser abordado durante a execução da atividade e ser retomado em um momento posterior. No entanto, isto não exclui a necessidade de elaboração e reflexão sobre os procedimentos que serão envolvidos no processo de ensino e aprendizagem para que, no decorrer da atividade, os sujeitos se apropriem criticamente dos conteúdos culturais, como uma estratégia política de instrumentalização para a prática social transformadora (SAVIANI, 2005).

Apesar de Baldani (2006) entender que o trabalho com os conteúdos prévios em sala de aula dificultaria o desenvolvimento das atividades de campo, as propostas foram discutidas coletivamente, e ficou claro que seria importante "buscar referenciais teórico-metodológicos que conceituariam e fundamentariam as atividades de campo e que consistiriam em materiais utilizados para posterior estudo" (BALDANI, 2006, p. 33).

Os objetivos daquele projeto foram definidos coletivamente, bem como foram definidos os textos teórico-metodológicos que fundamentariam o desenvolvimento da prática, ou seja, um texto sobre mapeamento ambiental (MEYER, 1991, 1992), como embasamento teórico para a busca e seleção dos ambientes onde desenvolveríamos as atividades de campo (Parque Zoológico; Jardim Botânico Municipal de Bauru e o próprio bairro Nobuji Nagasawa). Discutimos, também, sobre os conteúdos que eventualmente poderiam ser abordados no decorrer das atividades.

Decidimos, então, pela realização de uma atividade de reconhecimento do bairro, para que fossem analisadas as condições de execução do projeto, bem como dos assuntos que poderíamos abordar durante a atividade de campo. Selecionamos a região do Córrego Barreirinho, por ser este localizado próximo à escola e por termos ali observado questões ambientais que poderiam ser exploradas em uma atividade a ser realizada às margens do mesmo. Naquela região, pudemos observar: a ocorrência de erosão; a falta de manutenção da mata ciliar, quando presente; a presença de lixo orgânico, inorgânico e de construção civil; e a liberação de esgoto in natura no Córrego, entre outros.

Baldani (2006) esclarece que o objetivo geral das atividades de campo fundamentavase na ideia de tema gerador, em que os conteúdos de ensino deveriam ser extraídos da problematização da prática de vida dos educandos, valorizando a experiência de vida. Vejamos a ideia desenvolvida pela pesquisadora: 
[...] passamos, então, a trabalhar nessa segunda etapa de desenvolvimento das ações coletivas, de forma que a atividade de campo foi tratada como "tema gerador", com o objetivo de articular os estudos de forma coletiva e dialógica. Esses conteúdos de ensino devem ser extraídos da problematização da prática de vida dos educandos, ou seja, é importante a inserção de temas do cotidiano, da realidade social dos alunos. (BALDANI, 2006, p. 35-36)

Para efeito das análises que realizamos ao longo deste estudo, entendemos que o processo educativo tem de levar em conta a prática social dos alunos, problematizando-a, como frisa Saviani (2005). Embasados na concepção deste autor, consideramos que os conteúdos não podem ser restritos à problematização desta prática social, visto que haveria uma descaracterização do processo educativo, sobretudo em relação à educação ambiental crítica.

Os conteúdos a serem apropriados pelos sujeitos do processo educativo devem estar articulados ao objeto da educação que, de acordo com Saviani (2005, p. 13),

[...] diz respeito, de um lado, à identificação dos elementos culturais que precisam ser assimilados pelos indivíduos da espécie humana para que eles se tornem humanos e, de outro lado e concomitantemente, à descoberta das formas mais adequadas para atingir esse objetivo.

Portanto, os conteúdos não podem ser extraídos da experiência de vida dos educandos - embora esta possa ser levada em conta como ponto de partida para o início de um processo reflexivo-crítico sobre determinada questão que esteve ou está presente na realidade vivenciada por aqueles -, visto que o processo educativo visa a incorporação do saber historicamente elaborado, objetivando a transformação das relações sociais que são determinantes da prática social dos sujeitos. Assim, os conteúdos devem ser articulados neste âmbito.

No que diz respeito à educação ambiental crítica, Tozoni-Reis (2007) destaca que seus pressupostos se articulam com a pedagogia crítica alinhada às formulações de Saviani (2005), ou seja,

[...] diz respeito à teoria e a prática do processo intencional de apropriação de conhecimentos, idéias, conceitos, valores, símbolos, habilidades, hábitos, procedimentos e atitudes, ou seja, saberes e ações comprometidos com a emancipação dos sujeitos e a transformação destas relações de dominação historicamente determinadas. (TOZONI-REIS, 2007, p. 187)

Uma proposta de atividade de campo não pode se limitar, apenas, a uma nova visão na relação do conhecimento com a experiência de vida dos sujeitos, como uma alternativa ao processo de ensino e aprendizagem. Daí a importância de se trabalharem os conceitos de forma intencional e sistematizada, como estratégia política para transformação da sociedade, numa perspectiva de totalidade - universal e singular - da problemática ambiental, articulando 
a teoria à prática para que o sujeito se aproprie do conhecimento de forma dialética, incorporando-o e indo além, refletindo sobre o problema na sua raiz e superando o conceito de transmissão mecânica de conhecimentos acumulados historicamente (SAVIANI, 2005). Essa formulação coloca como essencial a articulação do conteúdo com a prática social do sujeito, possibilitando a superação entre a forma e o conteúdo no processo educativo.

\section{Projeto do Poder Público}

O projeto ambiental proposto pelo Poder Público foi realizado em parceria entre a Prefeitura Municipal e a Diretoria de Ensino (DE) de Bauru, com a finalidade de contribuir para a elaboração do Plano Diretor Participativo (PDP) daquele município. A partir desta proposta, por meio de nossa prática educativa como professor de Geografia da Escola Estadual Padre Antônio Jorge Lima, nos prontificamos a desenvolver o projeto ${ }^{6}$, no qual

[...] juntos, orientadores da Diretoria de Ensino, professores de Unidades Escolares de Bauru, alunos e comunidades dos bairros integrantes realizaram pesquisas e estudos sobre a bacia hidrográfica do Rio Bauru, os problemas relacionados à ocupação e degradação do meio ambiente, de acordo com suas microbacias, levando-se em consideração a construção de bairros em locais inadequados, sem planejamento algum, bem como diversos impactos ambientais decorrentes desses e de outros fatores. (TEIXEIRA, 2006, p. 1)

Assumindo o objetivo proposto como ponto de chegada do projeto, iniciou-se a caracterização dos problemas ambientais identificados no entorno da escola, tendo como tônica o processo educativo. Utilizando os procedimentos presentes na nossa prática educativa e voltados para o processo de ensino e aprendizagem, caracterizamos os aspectos naturais e sociais da microbacia do Córrego Barreirinho. Neste caso, tais procedimentos visaram:

- mostrar aos alunos, através de aulas teóricas, expositivas e práticas, o que é uma bacia hidrográfica; a importância de uma mata ciliar; a necessidade de se preservarem as nascentes e os rios, além de dar aos mesmos noções de urbanismo, ocupação e uso do solo;

- incentivar os alunos e a comunidade, juntamente com a associação de moradores, a participarem das reuniões elaboradas pelo Plano Diretor Participativo e a buscarem parcerias com órgãos competentes para a realização de melhorias nos bairros;

\footnotetext{
${ }^{6}$ Intitulado Estudo da qualidade ambiental da microbacia do Córrego Barreirinho: uma contribuição interunidades escolares como ferramenta orientadora para o plano diretor participativo de Bauru-SP. (TEIXEIRA, 2006).
} 
- levar os alunos a uma análise das características físicas, biológicas, socioambientais e geográficas da microbacia do Córrego Barreirinho; ao estudo do processo de apropriação das margens do Córrego, através de atividades de campo;

- enfatizar a importância das microbacias em um contexto local, regional e global, levando-se em consideração a totalidade da bacia hidrográfica. (TEIXEIRA, 2006, p. 2)

Embora elaborados empiricamente, estes procedimentos nos permitiram observar a relevância atribuída aos conteúdos relacionados ao processo de caracterização inicialmente proposto, os quais foram trabalhados em sala de aula, a partir de uma perspectiva teórica sistematizada e diretiva. Em um segundo momento, tais conteúdos foram articulados e retomados no próprio campo de estudo, vivenciando a realidade do espaço geográfico para, em uma etapa seguinte, serem reorganizados e problematizados em sala de aula. Nossa perspectiva era a de, ao final desse processo, voltarmos a campo para a caracterização dos principais problemas identificados naquele espaço. Como resultado do processo, um documento que caracterizava os problemas socioambientais enfrentados pela comunidade foi produzido e entregue, durante uma reunião do PDP de Bauru, realizada na Escola Estadual João Maringone, da qual também participaram as comunidades dos bairros situados na área da microbacia do Córrego Barreirinho.

Acreditamos que estas sejam as condições objetivas para se desenvolver um processo educativo pautado na lógica dialética e entendemos que a proposta daquele projeto criou tais condições, sobretudo por dar ênfase ao conteúdo, com possibilidade de estabelecer uma articulação com a prática. Nessa ótica, Saviani (2005, p. 114) destaca:

Quando se insiste na importância dos conteúdos, o que se está frisando aí é a necessidade de trabalhar a educação em concreto e não de forma abstrata. Com efeito, a lógica formal é a lógica das formas e, como o próprio nome está dizendo, abstrata. A lógica dialética é uma lógica concreta. É a lógica dos conteúdos. Não, porém, dos conteúdos informes, mas dos conteúdos em sua articulação com as formas.

No entanto, naquela ocasião, a falta de uma fundamentação teórica para o desenvolvimento das atividades gerou uma dicotomia entre a teoria e a prática, comprometendo o desenvolvimento do projeto e reproduzindo um processo educativo linear e abstrato, uma vez que os conteúdos foram trabalhados mais na condição de informes do que em articulação com as práticas, assim comprometendo a ênfase no desenvolvimento histórico de ocupação da microbacia, e colocando em segundo plano as contradições da sociedade. Tais práticas foram consideradas, portanto, como tendo um fim em si mesmas, e não como possibilidades de tornar os conteúdos concretos, os quais também tiveram um fim em si mesmos, permanecendo na abstração.

Esta situação nos permite afirmar que o fato de dispor de condições objetivas, pautadas apenas pela prática, não garante um bom desenvolvimento do processo educativo, pois, 
embora a prática seja fundamental, não é suficiente. Daí a importância da filosofia da práxis na formação do professor.

Mesmo não sendo este o foco deste estudo, acreditamos que a formação inicial e continuada de professores, numa perspectiva dialética, pauta-se pelas contribuições e formulações de Gramsci sobre a filosofia da práxis, para que o professor reflita sobre a prática, visando à superação dos problemas da realidade humana numa perspectiva histórica.

Após a abordagem teórica, sistematizada e diretiva dos conteúdos que estavam articulados com o desenvolvimento do projeto, cada unidade escolar identificou e caracterizou os problemas ambientais observados durante as atividades de campo realizadas ao longo da microbacia e, a partir da quantificação e descrição destes, foi elaborada uma análise qualitativa, com a participação dos alunos. Os principais problemas ambientais analisados foram: existência ou não de matas ciliares e das áreas de preservação permanente; poluição das margens; poluição das águas; identificação e análise dos principais focos de erosão, bem como dos processos de assoreamento; e a identificação e análise das voçorocas nas margens do córrego.

É importante observar que a nossa concepção de ambiente, naquela época, ainda era centrada nos aspectos naturais da microbacia, ou seja, a mesma que tínhamos quando da nossa participação no projeto desenvolvido por Baldani (2006). No entanto, consideramos que, a esta época, já tínhamos avançado um pouco mais, pois, ao tratarmos as questões acima identificadas, buscamos desenvolver oportunidades de reflexão para os alunos sobre os aspectos causais daqueles fenômenos, numa perspectiva histórica. Para tal, propusemos a reconstituição histórica de formação do Bairro Nobuji Nagasawa, trabalhando com fotografias aéreas para traçarmos um paralelo entre o aspecto daquele espaço geográfico antes da construção do bairro e os impactos atuais que, posteriormente, se mostraram visivelmente identificáveis na área, sendo este o principal fundamento das análises.

Entendemos que, embora focados na reconstituição histórica da formação do Bairro, o estudo naquele momento não se preocupou com as dimensões sociais, políticas e culturais que compunham o ambiente, com nos aponta Loureiro (2006, p. 53): "[...] relativo ao complexo, ao histórico, sem linearidades, sem simplificações e sem cair em propostas inseridas no paradigma da complexidade que recaem em idealismos e generalizações por minimizarem as dimensões sociais, inclusive a política".

Ao final das atividades, cada unidade escolar elaborou um relatório, e estes foram apresentados e discutidos nas reuniões então organizadas pela Prefeitura Municipal e realizadas em regiões a montante, no curso médio e a jusante da microbacia, objetivando garantir a participação das comunidades. Nesses relatórios foram apresentadas as propostas de intervenção que visavam à mitigação e reversão dos problemas ambientais caracterizados, e, finalmente, foi produzido um documento único, como já foi citado anteriormente, no qual constavam os problemas observados na área da microbacia, e que foi entregue à comissão do PDP de Bauru.

Embora este tenha sido um trabalho que fugiu do convencional, sobretudo com respeito à realidade em que se encontra o sistema público de ensino e a precariedade dos processos de formação e de atuação dos professores, entendemos que o objetivo de atingir a participação da comunidade não foi garantido. Aliás, poderíamos afirmar que, em última instância, não houve participação da comunidade na elaboração dos relatórios e nem nas discussões sobre as questões ambientais identificadas. Esta participação, na realidade, ficou restrita aos 
alunos que se envolveram no projeto, ou seja, aqueles que frequentavam duas salas de sextas séries do Ensino Fundamental, além de alguns moradores do bairro, que só estiveram presentes durante as reuniões realizadas pela comissão do PDP.

Acreditamos que este fato limitou uma apropriação mais consistente dos problemas ambientais enfrentados pelas pessoas que viviam no bairro e, neste sentido, entendemos que os projetos de educação ambiental não podem se limitar ao âmbito escolar. Entendemos que o projeto, apesar de ter enfatizado a prática em detrimento da teoria, explorou bem o processo educativo, na medida em que focou os conteúdos e os associou com o estudo de campo. No entanto, as atividades se limitaram à escola, ou seja, não atingiram a comunidade, não buscaram uma articulação mais efetiva com os moradores daquele bairro, portanto, um dos principais objetivos do trabalho foi comprometido: a participação da comunidade.

Poderíamos afirmar, ainda, que se alguma mudança foi alcançada, se algum princípio da educação ambiental foi contemplado, isto ocorreu apenas no nível individual e nos alunos, embora entendamos que:

[...] é necessário que estes se transformem em práticas sociais, assumidos pelos agentes da educação e legitimados pelo coletivo, pois é nesta dimensão que se opera objetivamente a mudança, reconhecendo que é insuficiente querer mudar o indivíduo sem mudar a realidade social em que este se situa como sujeito. (LOUREIRO, 2006, p. 109)

As mudanças individuais dos alunos estão relacionadas à apropriação dos conteúdos em si mesmos, ou seja, sem uma articulação mais ampla com a prática social. Desta maneira, apesar de aparecerem alguns dos princípios da educação ambiental crítica no Projeto, consideramos que a precariedade teórica sob esta dimensão da educação comprometeu os resultados alcançados, sobretudo os políticos, já que neste Projeto é que houve o envolvimento do Poder Público. Assim, os princípios da participação, da transformação, da emancipação e da interdisciplinaridade permaneceram na superficialidade, ou seja, mais no discurso do que na prática.

Nesta perspectiva, entendemos que a filosofia da práxis nos dá suporte para entendermos como esta pode contribuir para a formação inicial e continuada do educador ambiental, bem como dos professores, para que repensem suas práticas a partir da teoria, buscando suporte em uma pedagogia que esteja alinhada com tal filosofia. Uma pedagogia que seja crítica, dialética e que pense a realidade concreta a partir do movimento histórico dinâmico.

É à luz das concepções de educação ambiental e de pedagogia que se seguem, presentes no texto de Tozoni-Reis (2007), que buscamos aprofundar as análises dos resultados que apresentamos neste estudo, visando à superação dos limites apontados, sobretudo em relação ao processo educativo.

A pedagogia crítica na educação ambiental, partindo do princípio que a relação homem-natureza é construída pela história social, confere à educação a função de instrumentar os sujeitos para uma prática social ecológica e democrática. A educação ambiental crítica, transformadora e emancipatória, portanto, é formulada a partir da idéia de que a educação é prática social construída e construtora da humanidade, que, não 
podendo inventar uma realidade supra-histórica é construída no interior das relações sociais concretas de produção da vida social, contribuindo na construção dessas mesmas relações. A formação humana plena na perspectiva de superação radical da alienação, da exploração do homem pelo homem e da exploração da natureza pelos seres humanos, exige um processo educativo ambiental que instrumentalize os sujeitos para uma prática social ambiental. (TOZONI-REIS, 2007, p. 213-214)

\section{Conclusão}

Diante das discussões apresentadas, no que diz respeito ao processo educativo dos projetos que focaram a prática educativa escolar, entendemos que o trabalho de Baldani (2006), ao tratar das questões relacionadas ao meio sociooambiental, deu ênfase à dimensão da forma em detrimento do conteúdo. Isto significa dizer que o processo educativo priorizou as atividades de campo, colocando em segundo plano os conteúdos e os conceitos que poderiam ser explorados no processo de ensino e aprendizagem, apontando para uma dicotomia entre a forma e o conteúdo.

Não obstante, o trabalho de Teixeira (2006), apesar de focar os conceitos e conteúdos relacionados ao meio socioambiental, não buscou uma articulação com as formas e procedimentos numa perspectiva dialética. Observamos que a falta de fundamentação teórica fez com que as decisões fossem pautadas mais pela prática do que pela teoria, gerando uma dicotomia entre a forma e o conteúdo, comprometendo o desenvolvimento do projeto e reproduzindo um processo educativo linear e abstrato.

Neste sentido, os conteúdos a serem apropriados pelos sujeitos do processo educativo precisam estar articulados ao objeto da educação, ou seja, não podem ser extraídos apenas da experiência de vida destes sujeitos, mas devem visar à transformação das relações sociais que são determinantes da prática social dos mesmos.

Desta forma, a tese central defendida neste artigo entende que, ao se desenvolver um Projeto Ambiental, o trabalho educativo não pode se limitar à dimensão prática do processo educativo, pois, nesta perspectiva, os conteúdos historicamente produzidos pela humanidade são colocados em segundo plano, não cumprindo o principal objetivo e significado da educação: a humanização dos sujeitos. É nesta perspectiva que destacamos a superação da dicotomia entre teoria e prática por meio dos fundamentos da filosofia da práxis, entendendo-a como:

[...] a teoria que está empenhada em articular a teoria e a prática, unificando-as na práxis. É um movimento prioritariamente prático, mas que se fundamenta teoricamente, alimenta-se da teoria para esclarecer o sentido, para dar direção à prática. Então, a prática tem primado sobre a teoria, na medida em que é originante. A teoria é derivada. Isto significa que a prática é, ao mesmo tempo, fundamento, critério de verdade e finalidade da teoria. A prática, para desenvolver-se e produzir suas consequências, necessita da teoria e precisa ser por ela iluminada (SAVIANI, 2005, p. 141-142) 
A relação teoria e prática em projetos ...

Este é o ponto decisivo e desafiador para aqueles que estão comprometidos com a educação ambiental crítica, que visa à humanização dos sujeitos por meio da apropriação de conteúdos que contribuam para o enfrentamento das questões ambientais de nosso tempo.

Concluímos, pois, que um projeto de educação ambiental, na perspectiva crítica, ao se focar no processo educativo, deve dar centralidade aos conteúdos sociais, políticos, históricos e ambientais que podem ser explorados e trabalhados de forma intencional e sistematizada, (SAVIANI, 2005), em âmbito interdisciplinar.

A articulação dialética entre a teoria e a prática é imprescindível em qualquer processo educativo ambiental que coloque, em seu horizonte, a estratégia política como possibilidade de superação dos problemas socioambientais. Entendemos que esta perspectiva supera o conceito de transmissão mecânica dos conteúdos e as abordagens que dão ênfase aos procedimentos e formas do processo de ensino e aprendizagem, possibilitando, ao indivíduo, a tomada de consciência, e preparando-o para ações que visem à transformação.

\section{Referências}

BALDANI, R. C. Atividades de campo em educação ambiental: construção coletiva de diretrizes metodológicas. 2006. 123 f. Dissertação (Mestrado em Educação para Ciências) Faculdade de Ciências, Universidade Estadual Paulista, Bauru, 2006.

BARDIN, L. Análise de conteúdo. Lisboa: Edições 70, 1979.

BOGDAN, R.; BIKLEN, S. K. Investigação qualitativa em educação. Porto: Porto Editora, 1991.

GRÜN, M. Ética e educação ambiental: a conexão necessária. 11. ed. Campinas: Papirus, 2007.

HERMANN, N. M. A. Rousseau: o retorno a natureza. In: CARVALHO, I. C. M.; GRÜN, M.; TRAJBER, R. Pensar o ambiente: bases filosóficas para a educação ambiental. Brasília: Ministério da Educação: UNESCO, 2006. p. 93-110.

LÉVY-STRAUSS, C. Aula inaugural. In: ZALUAR, A. (Org.). Desvendando máscaras sociais. Rio de Janeiro: Francisco Alves, 1975. p. 211-244.

LOUREIRO, C. F. B. Problematizando conceitos: contribuições à práxis em educação ambiental. In: LOUREIRO, C. F. B.; LAYRARGUES, P. P.; CASTRO, R. S. (Org.). Pensamento complexo, dialética e educação ambiental. São Paulo: Cortez, 2006. p. 104-161.

Trajetórias e fundamentos da educação ambiental. São Paulo: Cortez, 2004.

LÜDKE, M.; ANDRÉ, M. E. D. A. Pesquisa em educação: abordagens qualitativas. São Paulo: E.P.U., 1986. 
Teixeira, L. A.; Talamoni, J. L. B.; Tozoni-Reis, M. F. C.

MEYER, M. A. A. A educação ambiental: uma proposta pedagógica. Em Aberto, Brasília, v.10, n. 49, p. 41-46, jan./mar. 1991.

Ecologia faz parte do espaço cotidiano. AMAE Educando, Belo Horizonte, n. 225, p. 13-20, mar. 1992.

SAVIANI, D. Educação socialista, pedagogia histórico-crítica e os desafios da sociedade de classes. In: LOMBARDI, J. C.; SAVIANI, D. (Org.). Marxismo e educação: debates contemporâneos. Campinas: Autores Associados, 2002. p. 223-279.

Escola e democracia. 38. ed. Campinas: Autores Associados, 2006.

Pedagogia histórico-crítica. 9. ed. Campinas: Autores Associados, 2005.

TEIXEIRA, L. A. Estudo da qualidade ambiental da microbacia do Córrego Barreirinho: uma contribuição interunidades escolares como ferramenta orientadora para o Plano Diretor Participativo de Bauru SP. In: CONGRESSO IBERO-AMERICANO DE EDUCAÇÃO AMBIENTAL, 5., 2006, Joinville. Anais... Joinville: Catalisa, 2006. 1 CD ROM.

Análise dos projetos ambientais desenvolvidos em um bairro de Bauru (SP) sob a perspectiva educativa. 2009. 223 f. Dissertação (Mestrado em Educação para a Ciência) - Faculdade de Ciências, Universidade Estadual Paulista, Bauru, 2009.

TOZONI-REIS, M. F. C. Contribuições para uma pedagogia crítica na educação ambiental: reflexões teóricas. In: LOUREIRO, C. F. B. A questão ambiental no pensamento crítico: natureza, trabalho e educação. Rio de Janeiro: Quartet, 2007. p. 177-221.

Artigo recebido em 08/12/12. Aceito em 19/05/13. 